\title{
Covid 19 as a factor damping globalization trends - structural analysis of local extrema at the level of EU countries
}

\author{
Josef Botlík $^{1, *}$ \\ ${ }^{1}$ Silesian University in Opava, School of Business Administration in Karvina, Department of \\ Mathematics and Informatics, Univerzitní náměstí 1934/3, 73340 Karviná, Czechia
}

\begin{abstract}
Research background: The authors participate in the creation of a model for monitoring and predicting the behavior of autonomous systems on a selected infrastructure for the analysis of current phenomena. Covid 19 dampens globalization trends and processes, especially free movement. The primary research aim was to identify changes in Covid19 indicators in area. The secondary aim was to find agreement in the behavior of selected globalization factors.

Purpose of the article: For the presented analysis, a research question was expressed how the EU states reacted to the change of local extremes of the pandemic. The paper presents spatial changes in the number of infected and dead in EU countries over time and compares these changes with selected changes in population movements and changes selected economic indicators.

Methods: Notably daily, monthly and quarterly data from Eurostat, OECD, ECDC and WHO at the level of EU countries were used for the analysis. Local extremes were identified by comparison, precedence analysis, structural analysis and simulation.

Findings \& Value added: The added value of the paper lies in the chosen method, which identifies local extremes using structural analysis in a geospatial context. In most cases, global analyzes fail to take into account the links between the analyzed factors and the geopolitical location of the region. The work presents the possibilities of analysis using precedent modeling, through which analyzes can be performed with respect to geographical links. The output is the identification of EU countries according to responses to changes in pandemic factors.
\end{abstract}

Keywords: globalization; covid19; model; Europe; precedent

JEL Classification: $F 60 ; \quad I 15$; $C 65$

\footnotetext{
* Corresponding author: botlik@,opf.slu.cz
} 


\section{Introduction}

Covid 19 is a phenomenon that is widely discussed due to its pandemic nature. The intensity and rate of deaths have forced this issue to be addressed at the level of national governments, at the supranational (e.g. EU) and global levels. The umbrella institution was undoubtedly the WHO. Due to the topicality of the topic, there is already an inexhaustible number of professional studies, specialized conferences and meetings of government officials are organized. The European Union is responding to the outbreak of COVID-19 and its consequences by adopting a wide range of measures in many areas (health, economy, research, border, mobility, etc.). A list of documents related to the common EU response to the COVID-19 pandemic has been published for example on EUR-Lex. A relatively comprehensive analysis of responses and restrictions to the virus in Europe and the European Union has been published by Aidnik (2021). It builds on the agreements set out in the 1992 Maastricht Treaty and the treatment of the sovereign debt crisis in 2010. It also refers to the "Manifesto for the Democratization of Europe" by leading French social thinkers since 2018, to discuss the reconstruction of eurozone governance. Due to the restrictions associated with minimizing the spread of Covid, this pandemic is currently the largest anti-globalization factor and it appears that some of the effects may be irreversible and lasting.

Also Nofre et al., (2020), in connection with government regulations and restrictions, points out that "... industry has stalled in Europe as a consequence of the COVID-19 pandemic and the unprecedented lock-down and physical distancing measures imposed by several national governments". However, the prevailing view is justifying government intervention. Blažek and Uhlír, (2020) mention in this context the theory of regional innovation systems, where it is possible to identify the fluctuation between divergent and convergent behavior of the region, even in shorter periods of time. From this point of view, it is clear that although there are significant sensitivity differences to disparities and there are factors that are more or less resilient to regional disparities, in some cases regional processes can be observed, which are influenced by regional parameters but has a global character. Undoubtedly, such processes include pandemic processes, for which regional disparities are rather a catalyst (poverty, level of health care, state policy), but they show a global character, especially unlimited and uncontrollable spread in space. Therefore, it is necessary to apply regional policy in a pandemic, as a tool to reduce regional disparities, allow (in the concept of a set of economic and social policies) to regulate these globalization factors. Most studies are based on statistics of increases in Covid cases and deaths, but some authors recommend analyzing reproductive numbers and deaths (Yuan et al., 2020). In our paper, we will lean towards standard analyzes of the number of Covid cases and deaths. The aim of the paper is to map the spatial changes in the number of infected and dead in EU countries over time and to compare these changes with changes in selected economic indicators.

\section{Methods}

\subsection{Theoretical background, methods}

National restrictions were intended to slow down or eliminate the spread of socio-economic disparities. The methods of analysis are therefore based on methods of structural and spatial regional analysis, which are characterized by the use of infrastructures that depend on geopolitical distribution. The basis of the analyzes is a precedent analysis, which indicates increases in the values of the monitored factor with respect to the surroundings. In this way, local and global extremes of the monitored quantities and changes in these extremes over time are identified. Spatial interconnections can be given by physical dependencies (proximity of subjects, common boundary points, presence of physical, e.g. road connection, 
etc., or are purposefully generated by virtual infrastructure, for example, based on geographical coordinates and selected parameters, most often minimum distances. The number of minimum distances and other infrastructure parameters are defined, such as triangulation of found minimum adjacencies or edge repetitions. The generation of virtual infrastructure on regional geopolitical objects encounters problems associated with the uneven distribution of neighboring objects and the different size of objects, which can negatively affect the parameters of the infrastructure. The analysis using precedents is based on graph theory and systems analysis, the theoretical basis is described, for example, by Langefors (1981). Efficiency is given by the conversion of numerical data into binary form, which enables more efficient use of mathematical models and significantly expands the capacity of processed data, which is a cardinal problem in regional analyzes. Many authors, such as Rozmrinová (2020), use basic statistical tools and comparisons in this context. However, regional contexts are addressed more as "measuring points", environmental and geographical contexts are not considered. More sophisticated methods are given, for example, by Undurraga et.al., (2021), where the authors use the Monte Carlo method for prediction. Even these authors do not draw conclusions in the geographical context. Koenig and Dressler (2021) mention indications of a regional understanding of analysis with regard to certain accessibility of the environment and the need to combine analytical methods. Wilinski and Szwarc (2021) state the connection between the prediction of development in connection with the spread of Covid and the growth phases of the epidemic and the need for simulation tools (Matlab). In the list of literature related to regional analyzes Covid, it is necessary to mention the study of Rebaz (2021), which uses, similarly to our model, matrix and graph theoretically oriented analyzes, uses advanced mathematical functions (Laypunov function, differential equations, etc.). Our model is based on the same tools (matrix record, graph theory), but we use an incomparably simpler apparatus of binary comparisons for processing and analysis. The presented method is not qualitatively comparable with specific similar research, because it combines previously independently applied methods. While methods of network analysis in the sense of finding incidents are relatively common, their connection with the construction of general infrastructure and identification of local extremes using precedents in the sense of analysis of local extremes of regional factors is new.

\subsection{Model a data}

The analysis itself was performed in several steps. In the first phase, an infrastructure model was generated and precedents were calculated in the monitored interval. Precedences for individual data series were determined at the state level. In the second phase, factors that could be significantly influenced by the development of the pandemic were compared on the basis of comparison. This comparison indicated time intervals with disproportions that could be affected by Covid 19. Disproportions were monitored depending on the number of cases and the number of Covid deaths in each country per capita. To find local extremes, the minimum geographical distances of the EU states were chosen as links based on GPS coordinates, which took into account the dislocation of states in space and their density in the region. Due to the unavailability of data, the set of countries has been reduced. Data were compared from daily, monthly and quarterly data from Eurostat, OECD, ECDC and WHO at the level of EU countries. Similar databases are used by most studies, such as Yuan et al., (2020). At present, however, a number of comprehensive databases are also being created as a result of secondary data collection and secondary analysis (Omrani et al., 2021) All calculations and modeling are performed using MS Excel and VisualBasic. The analysis of complex data was performed using the MS Excel Analytical Tools - Correlation add-in.

The search for infrastructure is carried out by random, repeated passage through all states. For each state, a specified number of geographically closest states is searched. Figure 1 on 
the left shows the infrastructure in which the 3 closest states were searched, the search was performed by 10 random passes, the repetition of edges was allowed. The resulting infrastructure had all the edges identified in all ten passes (except one). However, the infrastructure in the Central European region was insufficient. Another version (Fig. 1 in the middle) was modified so that the rewriting of edges was allowed, the edges identified in ten or more percent of passes were accepted. The resulting infrastructure is shown in Figure 1 on the right. For the analysis itself, an infrastructure with two minimum edges with forbidden edge repetition was chosen (BA edge is not allowed when $\mathrm{AB}$ edge exists, edges detected in more than $50 \%$ of passes are accepted. Different bond shades indicate different identification numbers, with regard to the distribution of countries in space.

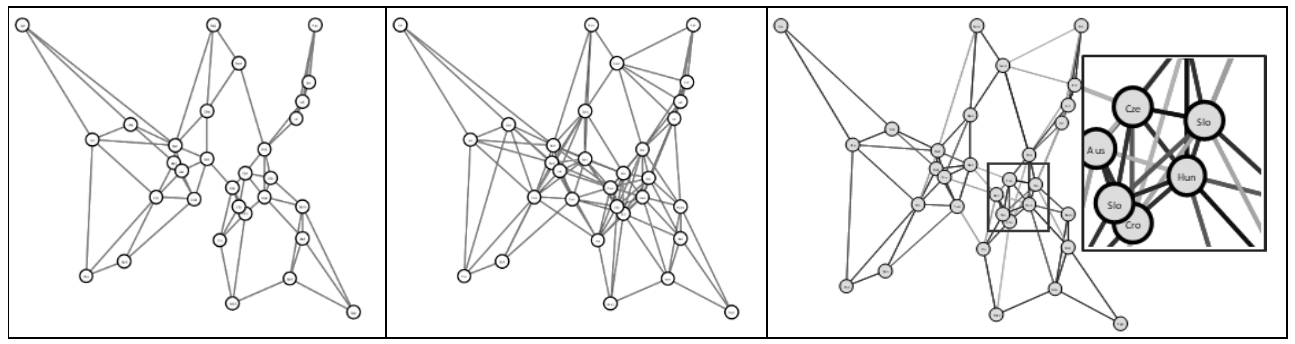

Figure 1. Infrastructure for analysis.

Source: author (2021)

Precedences were observed on the selected infrastructure, which show a change in the quantity. Mazzucchelli et al., (2020) used similar methods of spatial analysis based on gradient detection in combination with correlation analysis. Finally, data on population movements were not used for this contribution, as this movement was too dependent on state policy, but in most cases the cross-border movement of employees was not restricted. The development of foreign trade is also subject to restrictions WTO Members have adopted various trade-related measures under their domestic laws in response to the outbreak of Covid-19. Glockle (2021) discusses ways to exempt or justify quantitative export restrictions or bans. The data Exports in goods (value), Monthly International Merchandise Trade (IMTS) - Headline Series, Percentage change on the same period of the previous year and Percentage change from previous period were chosen to compare foreign trade. Other data series are GDP and main components (output, expenditure and income) [NAMQ_10_GDP_custom_77309], Chain linked volumes, percentage change on previous period and Chain linked volumes, percentage change compared to same period in previous year. Analyzes of Covid's impacts on GDP are relatively common, for example, we recommend the Salis study (2021). Precedences were gradually calculated for individual weekly intervals for the number of Covid cases and deaths, the time interval was 1 week 2020 to 37 weeks 2021. For GDP, precedences were calculated quarterly in the interval Q1 / 2019 to Q2 / 2021. The values from 2019 were used to compare seasonal fluctuations. Exports were calculated in the monthly intervals January / 2019 to August 2021.

\section{Results}

Figure 2 shows the course of values (from left to right) for information. Exports in goods, GDP, number of new Covid cases, and number of new deaths. By adjusting the scale, comparison and identification of non-standard changes of quantities were performed (Fig. 3). 


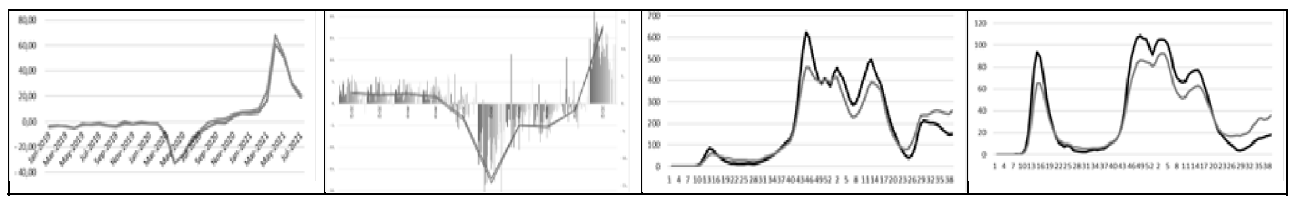

Figure 2. GDP, Export, cases, deaths.

Source: author (2021)

Based on this comparison, intervals of weeks 10 to 19 , weeks 25 to 28 , weeks 37 to 45 of 2020, 10 to 16 were identified on selected quantities. and weeks 22 to 30 of 2021 .

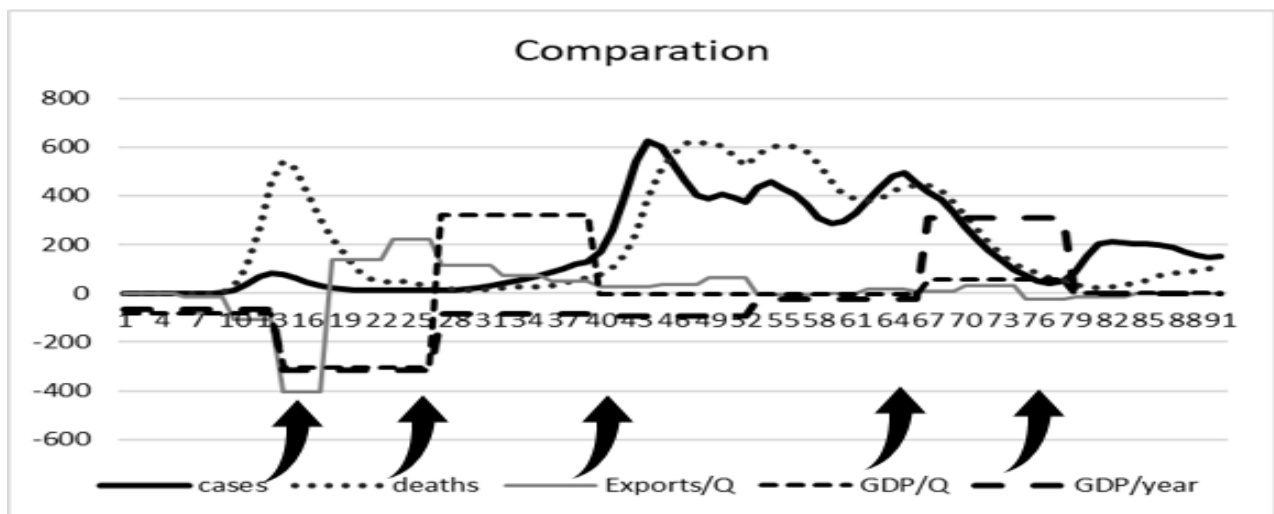

Figure 3. Primary comparation.

Source: author (2021)

Figure 4 shows in the first row the year-on-year changes in GDP from left to right in Q1, Q2, Q3 / 2020. The second line shows Export / year.

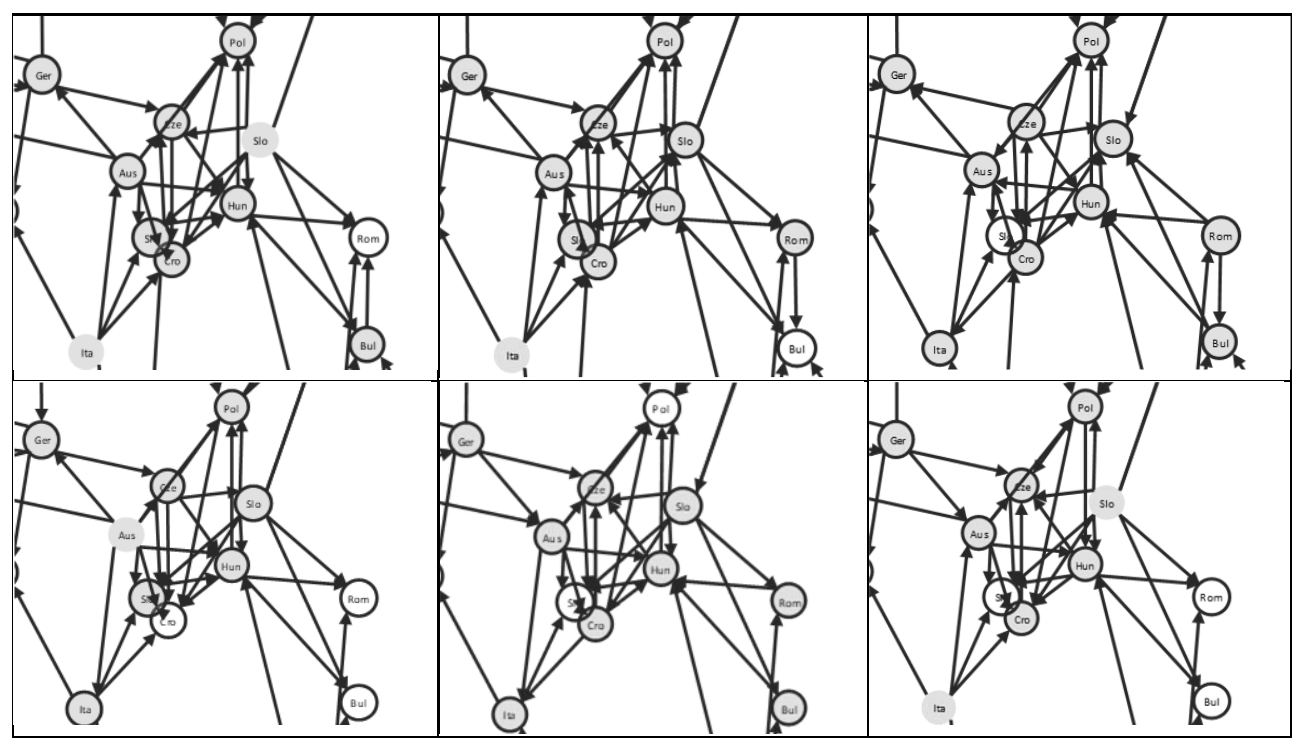

Figure 4. Precedence - GDP, Export.

Source: author (2021) 
A node without a boundary has the lowest values of the quantity with respect to the surroundings, it is a precedent of all surrounding nodes. A node without tinting has the highest values with respect to the surroundings. Figure 4 shows changes in GDP Q1 / Q2 and GDP Q2 / Q3, where the local maximum gradually shifted from Romania, through Bulgaria to Slovenia, the local minimum gradually shifted from both Slovakia and Italy. Similar and more significant changes can be traced to exports (March, May, August 2020). Based on these precedents, percentages of precedents with respect to the number of existing edges were calculated.

\begin{tabular}{|c|c|c|c|c|c|c|c|c|c|c|c|c|c|c|c|c|c|c|c|c|c|c|c|c|}
\hline & \multicolumn{10}{|c|}{ deaths } & \multicolumn{10}{|c|}{ cases } & \multicolumn{2}{|c|}{ Export } & \multicolumn{2}{|c|}{ GDP } \\
\hline & 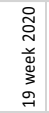 & 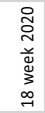 & 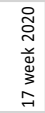 & 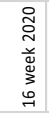 & 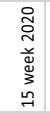 & 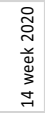 & 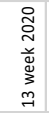 & 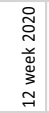 & 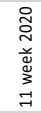 & 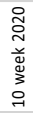 & 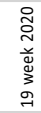 & 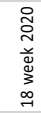 & 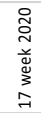 & 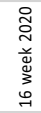 & 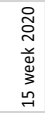 & 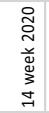 & 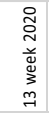 & 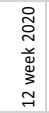 & 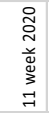 & 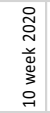 & 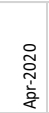 & 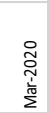 & $\begin{array}{l}\text { శ్ } \\
\text { ல் } \\
\text { ஸे }\end{array}$ & $\begin{array}{l}\text { ơ } \\
\text { ర్ } \\
\text { ర్ }\end{array}$ \\
\hline Austria & 75 & 50 & 38 & 38 & 25 & 25 & 25 & 25 & 25 & 13 & 75 & 75 & 38 & 38 & 38 & 25 & 25 & 25 & 38 & 13 & 13 & 50 & 75 & 88 \\
\hline Belgium & 17 & 0 & 0 & 0 & 0 & 0 & 0 & 0 & 33 & 67 & 17 & 17 & 0 & 0 & 17 & 33 & 33 & 33 & 17 & 100 & 33 & 17 & 67 & 67 \\
\hline Bulgaria & 40 & 40 & 40 & 80 & 80 & 80 & 80 & 40 & 20 & 0 & 20 & 60 & 80 & 80 & 100 & 100 & 80 & 60 & 40 & 40 & 0 & 0 & 0 & 20 \\
\hline Czechia & 86 & 86 & 86 & 57 & 43 & 43 & 43 & 71 & 57 & 0 & 43 & 43 & 29 & 29 & 29 & 29 & 43 & 43 & 43 & 29 & 86 & 86 & 29 & 43 \\
\hline Denmark & 80 & 80 & 80 & 80 & 60 & 60 & 60 & 60 & 80 & 20 & 20 & 60 & 60 & 80 & 80 & 80 & 100 & 60 & 20 & 100 & 0 & 0 & 20 & 20 \\
\hline Estonia & 20 & 20 & 40 & 40 & 40 & 40 & 60 & 80 & 60 & 20 & 60 & 40 & 40 & 40 & 20 & 0 & 0 & 0 & 0 & 20 & 20 & 40 & 20 & 40 \\
\hline Finland & 50 & 50 & 25 & 25 & 25 & 25 & 25 & 25 & 25 & 0 & 25 & 25 & 25 & 25 & 50 & 75 & 75 & 50 & 50 & 50 & 50 & 100 & 50 & 50 \\
\hline France & 57 & 57 & 43 & 29 & 29 & 29 & 43 & 57 & 14 & 0 & 86 & 86 & 100 & 100 & 100 & 86 & 86 & 57 & 57 & 29 & 86 & 86 & 86 & 100 \\
\hline Germany & 57 & 57 & 43 & 57 & 86 & 86 & 86 & 86 & 86 & 29 & 57 & 57 & 71 & 57 & 57 & 57 & 57 & 57 & 86 & 43 & 71 & 71 & 71 & 71 \\
\hline Italy & 0 & 0 & 0 & 0 & 0 & 0 & 0 & 0 & 0 & 0 & 0 & 0 & 0 & 0 & 20 & 20 & 20 & 0 & 0 & 0 & 100 & 100 & 100 & 100 \\
\hline Latvia & 80 & 60 & 80 & 100 & 80 & 80 & 100 & 60 & 40 & 20 & 60 & 60 & 100 & 100 & 60 & 60 & 20 & 40 & 40 & 60 & 0 & 0 & 80 & 80 \\
\hline Lithuania & 60 & 80 & 60 & 40 & 40 & 40 & 20 & 20 & 40 & 20 & 100 & 100 & 40 & 40 & 40 & 20 & 60 & 60 & 80 & 40 & 60 & 20 & 0 & 0 \\
\hline Luxemb & 57 & 57 & 71 & 57 & 43 & 57 & 43 & 14 & 14 & 43 & 43 & 29 & 14 & 14 & & 0 & 0 & 0 & 43 & 71 & 100 & 100 & 29 & 14 \\
\hline Malta & 100 & 100 & 100 & 67 & 33 & 100 & 100 & 67 & 67 & 33 & 33 & 33 & 33 & 33 & 33 & 33 & 33 & 33 & 33 & 100 & 0 & 0 & 67 & 0 \\
\hline Netherlands & 38 & 38 & 50 & 38 & 38 & 2 & 13 & 25 & 38 & 13 & 50 & 38 & 50 & 50 & 50 & 63 & 50 & 75 & 63 & 25 & 25 & 38 & 50 & 50 \\
\hline Norway & 100 & 100 & 100 & 100 & 100 & 100 & 100 & 100 & 67 & 33 & 100 & 100 & 100 & 100 & 100 & 33 & 0 & 0 & 0 & 0 & 100 & 100 & & 0 \\
\hline Poland & 56 & 44 & 44 & 78 & 67 & 78 & 78 & 44 & 33 & 0 & 11 & 22 & 56 & 67 & 78 & 78 & 89 & 89 & 100 & 67 & 67 & 44 & 22 & 11 \\
\hline Portugal & 100 & 100 & 100 & 100 & 100 & 100 & 67 & 67 & 100 & 67 & 33 & 33 & 67 & 67 & 67 & 33 & 33 & 100 & 100 & 100 & 67 & 33 & 33 & 33 \\
\hline Romania & 0 & 0 & 25 & 25 & 0 & 0 & 25 & 75 & 75 & 0 & 0 & 0 & 0 & 0 & 0 & 0 & 0 & 75 & 75 & 25 & 0 & 0 & 25 & 0 \\
\hline Slovakia & 100 & 100 & 100 & 89 & 100 & 100 & 89 & 78 & 33 & 0 & 89 & 89 & 67 & 78 & 89 & 78 & 67 & 56 & 33 & 44 & 100 & 100 & 56 & 100 \\
\hline Slovenia & 33 & 50 & 50 & 33 & 33 & 33 & 33 & 50 & 50 & 17 & 83 & 83 & 100 & 67 & 50 & 50 & 33 & 33 & 17 & 67 & 33 & 17 & 33 & 50 \\
\hline Spain & 0 & 0 & 0 & 0 & 0 & 0 & 0 & 0 & 0 & 67 & 33 & 33 & 0 & 0 & 0 & 0 & 0 & 0 & 33 & 33 & 33 & 67 & 100 & 67 \\
\hline
\end{tabular}

Figure 5. Precedence, first interval.

Source: author (2021)

In the next phase of the research, correlations between the determined values of precedence were determined. Table 1 shows the simplified numbers of correlations, the first column shows the limit of the coefficient and then the number of detected correlating states. At the same time, the maximum and minimum values of the correlation coefficient are given.

Table 1. Agreement of the correlation coefficient

\begin{tabular}{|c|c|c|c|c|c|}
\hline & All & GDP & Export & Cases & Deaths \\
\hline$>\mathbf{0 , 8}$ & 0 & 5 & 7 & 0 & 0 \\
\hline$>\mathbf{0 , 5}$ & 8 & 55 & 36 & 21 & 9 \\
\hline$<-\mathbf{0 , 5}$ & 0 & 75 & 46 & 1 & 5 \\
\hline$<-\mathbf{0 . 8}$ & 0 & 5 & 5 & 0 & 0 \\
\hline max & 0,60 & 0,91 & 1,00 & 0,64 & 0,69 \\
\hline $\min$ & $-0,40$ & $-1,00$ & $-0,98$ & $-0,52$ & $-0,58$ \\
\hline
\end{tabular}

Source: author (2021) 
he overall correlations show the similarity of spatial development in Finland-Austria, Bulgaria-Poland, Estonia-Norway-Greece-Iceland, Italy-Germany-Latvia and SlovakiaSwitzerland. This similarity is not given by the identical development of the real values of the investigated factors but by the spatial orientation of the quantities, specifically by the number and changes of increases / decreases in the values in the surrounding states. This similarity is not significant, the correlation coefficient $\mathrm{R}$ is from the interval $(0.5,0.6)$. It is obvious that this correlation is mainly based on the correlation in the number of cases. In this criterion, it is possible to identify similar groups of states (or groups with the same core of states), a total of 15 states have this tendency, Bulgaria, Czechia, Croatia, Estonia, Finland, Latvia, Lithuania, Norway, Germany, Poland, Greece, Italy, Malta, Poland and Slovakia. If we observe correlations of exports, then strong correlations are evident in less developed economies, Malta, Romania, Bulgaria and Croatia. The similarity (spatial correlation) on a shorter interval is more obvious (Table 2). In such a short interval, however, it is not possible to determine correlations for GDP and exports (with respect to the measurement interval), so a decrease and increase is recorded. The number of Covid cases has a similar course in 12 countries ( 22 cases of correlation with $\mathrm{R}>0.8$ ), the negative correlation is also relatively significant (18 correlations in 10 countries). There is a positive correlation of deaths in 10 countries (Austria, Belgium, Bulgaria, Czechia, Estonia, Germany, Latvia, the Netherlands, Spain, and a negative correlation in Belgium, Denmark, Ireland, Norway, Slovakia, Spain and Sweden). countries (Norway) had both positive and negative correlations. The table also shows that the development of exports was unchanged in 19 countries and was more stable than the development of GDP (unchanged in 14 countries). The number of precedents increased for GDP in Croatia, Hungary, Luxembourg, Malta, Poland, Romania, Spain, Sweden, the decline was recorded in Austria, Bulgaria, the Czech Republic, Estonia, France, Greece, Slovakia and Slovenia. In the case of exports, there was an increase in the number of precedents in Belgium, Hungary, Lithuania, Poland, Portugal and Slovakia, while only in Hungary and Poland there was an increase in both factors. Decreases in the number of precedents were recorded in Austria, Estonia and Finland, Greece, the Netherlands and Spain. The decline in both factors was in Austria, Estonia and Greece.

Table 2. Agreement of the correlation coefficient - First interval

\begin{tabular}{|c|c|c|c|c|c|c|c|}
\hline & All & Cases & \multicolumn{2}{|c|}{ Deaths } & & GDP & Export \\
\hline$>0,8$ & 1 & 22 & 18 & & $\nearrow$ & 8 & 6 \\
\hline$>0,5$ & 38 & 84 & 121 & & $\searrow$ & 9 & 6 \\
\hline$<-0,5$ & 37 & 100 & 67 & & $\rightarrow$ & 14 & 19 \\
\hline$<-0.8$ & 2 & 18 & 13 & & & & \\
\hline $\max$ & 0,82 & 0,92 & 1,00 & & & & \\
\hline $\min$ & $-0,85$ & $-0,96$ & $-0,97$ & & & & \\
\hline
\end{tabular}

Source: author (2021)

\section{Discussions}

The result of the counterfactual analysis (Salisu et al., 2021) indicates that the impact of COVID-19 shock on real GDP is pervasive and more prevalent in the developed than the emerging economies, his model forecasts real GDP growth of emerging countries more precisely, he sees the shortfalls in the projections for advanced economies to the efficacy of fiscal and unconventional monetary policies to speed up the recovery in these countries. These conclusions were not confirmed in our research, the shifts of extremes were across countries, there was no significant difference between developed and emerging economies. Mazzucchelli's conclusions (Mazzucchelli et al., 2020) were not confirmed. Mazzucchelli 
claims in his research that in Europe, there is a west to east (from highest to lowest) gradient in the mortality of Covid-19. This does not apply in the case of extremes, the trend of eastwest shifts is not apparent. In connection with the first wave and changes between 15-20 weeks 2020, the outcomes of our study indicate, similarly to Pardhan and Drydakis (2021) that, in the first wave of the pandemic in Europe, a country's GDP per capita might be associated with a lower rate of new COVID-19 cases. Pardhan and Drydakis study concludes by suggesting that in European regions a country's economic performance should be a critical health priority for policymakers. The significance of similar analyzes can therefore be significantly increased by the addition of non-pharmaceutical restrictions. These are restrictions at the state level, stated for example at the OECD.Stat. Presented secondary comparisons were also published by Dye et al., (2020): “...Rather, countries with fewer deaths locked down earlier, had shorter epidemics that peaked sooner and smaller populations. Consequently, as lockdowns were eased". These are approximately 70 recommended forms of restriction. Figure 6 shows the application of the StayHomeOrder restriction: Stay-at-home orders for the general population (these are enforced and also referred to as 'lockdown').

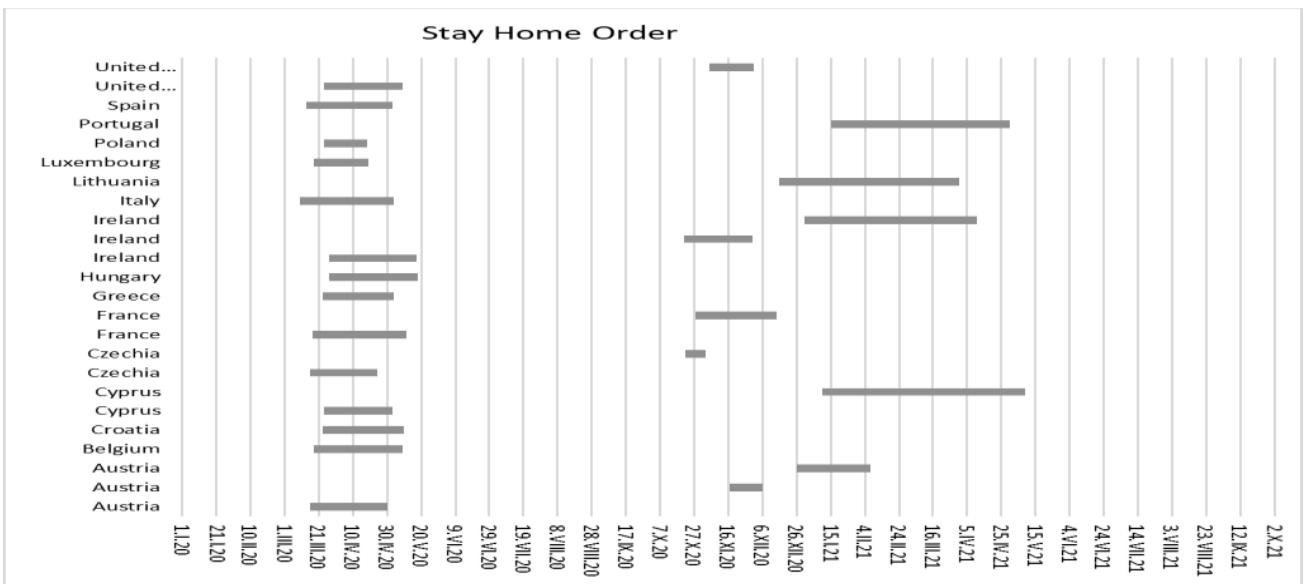

Figure 6. Stay Home Order restriction.

Source: author (2021)

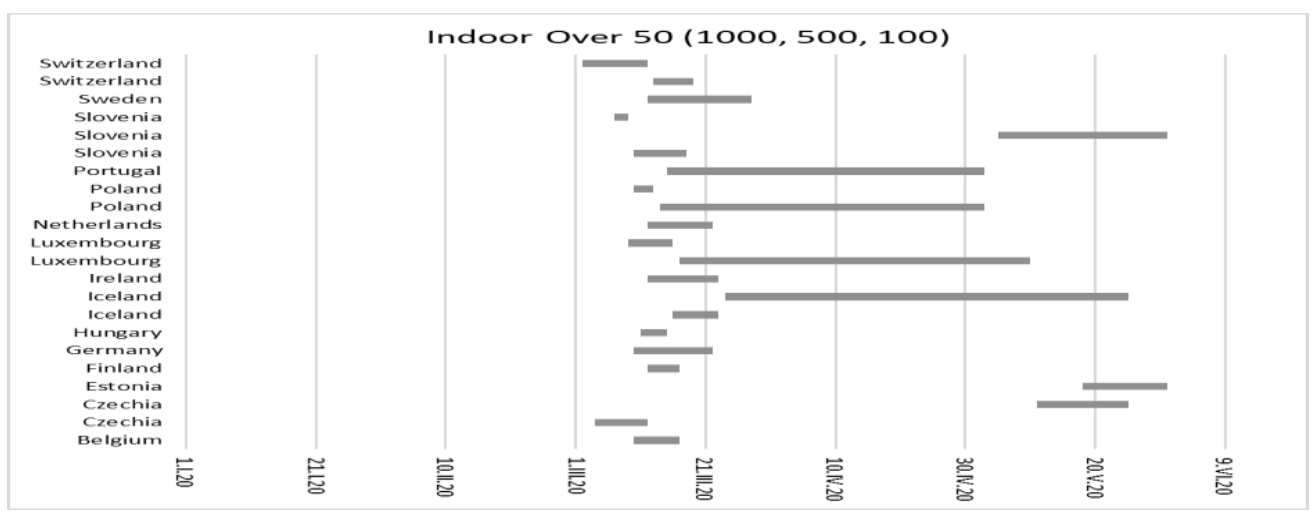

Figure 7. Indoor over XX restriction.

Source: author (2021) 
It is evident that 16 countries applied this restriction, some of them repeatedly (Cyprus, Czechia, France, UK 2x, Austria, Ireland, 3x). It is clear that most countries have not applied this type of restriction. Similar restrictions (IndoorOver50 / 1000, 500, 100: interventions are introduced to limit internal mass / public gatherings over 50/1000, 500, 100 participants) applied by countries in 64 cases, most often Iceland (9x), Switzerland (8x), Czechia 7x, If we narrow the restriction to the first observed interval, it is evident that this restriction was not used much in the first wave, but it was applied repeatedly (Figure 7).

Cross et al., (2020) also claimed and investigated how restrictive interventions affected by infection rates and gross domestic product (GDP). While greater restrictions generally slowed viral transmission, timing was fundamental: governments who responded to the pandemic faster saw greater reductions in viral transmission $(\mathrm{p}=0.013)$, but worse decreases in GDP $(p=0.044)$. According to Cross et al., (2020), "response stringency has a greater effect on GDP than infection rates, which are instead affected by the timing of COVID-19 interventions. Attempts to mitigate economic impacts by delaying restrictions or decreasing stringency may buoy GDP in the short term but increase infection rates, the longer-term economic consequences of which are not yet fully understood. As highly restrictive interventions were successful in some but not all countries, decision-makers must consider whether their strategies are appropriate for the country on health and economic grounds ".

\section{Conclusion}

An important feature of the precedent analysis is that an increase in the number of precedents may indicate two conditions, a decrease in values in the vicinity or an increase in values in the examined state. It is therefore not important what was and the change in the local extreme caused, it is important that the change occurred. This allows you to better monitor changes in space. The paper presents the possibilities of precedent analysis supplemented by comparison and correlation analysis. States were identified in which there were significant changes in the observed factors during the pandemic due to the significant surroundings of these states, not due to absolute changes in the factors. The paper presents a part of the research, a comparison of the whole interval and the first identified disproportion.

Precedence analysis also allows the comparison of longer spatial dependencies (using indirect, multiple precedents). In this way, the analysis can be extended to broader spatial connections in the future. Part of the analyzes had to be reduced because no data were relevant. However, due to intensive pandemic research, the data are further refined and comprehensive third-party databases are created, in addition to official WHO databases, Eurostat, a relatively extensive database of socio-economic data at NUTS 3 level published by Omrani et al., (2021).

\section{Acknowledgements}

The paper was prepared within the project IP / 01/2021 Institutional Support of SU OPF in Karviná.

\section{References}

1. Aidnik, M. (2021). On social europe after covid-19. Trames-Journal of the Humanities and Social Sciences, 25(2), 173-190.

2. Blažek, J., \& Uhlíř, D. (2020). Teorie regionálního rozvoje: nástin, kritika, implikace. Praha: UK in Prague, Karolinum Press. ISBN 987-80-246-4566-7. 
3. Cross, M., Ng, S. K., \& Scuffham, P. (2020). Trading health for wealth: The effect of covid-19 response stringency. International Journal of Environmental Research and Public Health, 17(23).

4. Dye, C., Cheng, R. C. H., Dagpunar, J. S., \& Williams, B.G. (2020). The scale and dynamics of COVID-19 epidemics across Europe. Royal Society Open Science, 7(11).

5. Glockle, C. (2021). Exempting and Justifying Covid-19 Related Export Restrictions Under WTO Law.

6. Legal issues of economic integration, 48(2), 201-221, D: covidwho-1282958.

7. Koenig, A., \& Dressler, A. (2021). A mixed-methods analysis of mobility behavior changes in the COVID-19 era in a rural case study. European Transport Research Review, 13(1), Article 15.

8. Langefors, B. (1981). Teoretická analýza informačních systémů. Bratislava: Vydavatelstvo technické a ekonomickej literatury. ISBN bez ISBN.

9. Mazzucchelli, R., Agudo, D. A., Dieguez, C. E. M., \& Crespi, V. N. (2020). Democracy and Covid-19 mortality in Europe. Revista Espanola de Salud Publica, 94. ID: covidwho-613678.

10. Nofre, J., Garcia-Ruiz, M., Fuarros, I. S., \& Pires, C. V. (2020). Hopes and uncertainties in the nightlife industry of post-Covid-19 Europe. Finisterra - Revista Portuguesa De Geografia, 115, 249-254.

11. Omrani , H., Modroiu, M., Lenzi, J., Omrani, B., Said, Z., Suhrcke, M., Tchicaya, A., Nguyen, N., \& Parmentier, B. (2019). COVID-19 in Europe: Dataset at a sub-national level. Data in brief, 35.

12. Pardhan, S., \& Drydakis, N. (2021). Associating the change in new covid-19 cases to GDP per capita in 38 European countries in the first wave of the pandemic. Frontiers in Public Health, 8.

13. Rebaza, J. (2021). On a model of covid-19 dynamics. Electronic Research Archive, 29(2), 2129-2140.

14. Rozmrinová, J. (2020). New coronavirus disease - data from the regions of the Czech Republic. In XXIII. mezinárodni kolokvium o regionálních vědách. Sborník přispěvků. Brno: Masarykova univerzita, 416-422.

15. Salisu, A. A., Adediran, I. A., \& Gupta, R. (2021). A note on the COVID-19 shock and real GDP in emerging economies. Emerging Markets Finance and Trade.

16. Undurraga, E.A., Chowell, G., \& Mizumoto, K. (2021). COVID-19 case fatality risk by age and gender in a high testing setting in Latin America: Chile, March-August 2020. Infectious Diseases of Poverty, 10(1).

17. Wilinski, A., \& Szwarc, E. (2021). A classification of countries and regions by degree of the spread of coronavirus based on statistical criteria. Expert Systems with Applications, 172, Article 114654.

18. Yuan, J., Li, M., Lv, G., \& Lu, Z. K. (2020). Monitoring transmissibility and mortality of COVID-19 in Europe. International Journal of Infectious Diseases, 95, 311-315. 